\title{
Comparison Between Blood Glucose Levels of Periodontal Pockets with Fingertips Patients with Type2 Diabetes Mellitus.
}

\author{
Umi Ghoni Tjiptoningsih ${ }^{1}$, Nunung Rusminah ${ }^{2}$ Agus Susanto $^{3}$ \\ \{umighonitjiptoningsih@dsn.moestopo.ac.id ${ }^{1}$, nunung.rusminah@fkg.unpad.ac.id² \\ agus.susanto@fkg.unpad.ac.id $\left.{ }^{3}\right\}$ \\ ${ }^{1}$ Departement of Periodontic , Faculty of Dentistry, Prof. Dr. Moestopo (Beragama) \\ University, Jakarta Selatan. Indonesia \\ ${ }^{2,3}$ Departement of Periodontic , Faculty of Dentistry, Padjadjaran University, Bandung. \\ Indonesia.
}

\begin{abstract}
Periodontitis is an oral health problem that has a fairly high prevalence in the community reaches $96,58 \%$ closely related to systemic disease such as Diabetes Melitus. The purpose of this study to analyze the results of blood sugar levels taken from periodontal pockets and the fingertips of patients with type 2 diabetes melitus and compares the results of blood sugar levels taken from the periodontal pocket with the tip of a finger in patients with type 2 diabetes melitus. This Research Methode is checked his blood sugar levels were taken at the time of gingival probing and pricking fingertips using Accu-check Glucometer Nano Performance. Statistical analysis using Student's t-test and Pearson correlation significance test The Results of this study is Here were no differences in blood sugar levels when (mg / dl) in both chronic periodontitis with diabetes mellitus and without diabetes mellitus between the fingertips and the periodontal pocket with a $p$-value $\geq 0.05$, where the $p$-value in patients diabetes mellitus 0.911 and p-value 0.982 without diabetes mellitus. Finaly Examination of the blood sugar levels of periodontal pockets during the examination together with blood sugar levels while at the fingertips, so that the inspection can be done at the dentist's office without going to the laboratorium.
\end{abstract}

Keyword: Diabetes melitus, Finggertips, poket periodontal, Accu-check Glucometer Nano Performance

\section{Introduction}

Periodontitis is the most common disease in the supporting tissues of the teeth involving the gingiva, cementum, periodontal ligament, alveolar bone associated with plaque involvement. In general, periodontitis begins with gingivitis, but not every gingivitis develops into periodontitis. This condition is influenced by the number and level of virulence of microorganisms that develop in the body's response as an immune defense, as well as genetic and hereditary factors.[1],[2],[3]. Periodontal disease is a dental and oral health problem which has a high prevalence in the community reaching $96.58 \%$ in all age group. Periodontal disease is closely related to systemic 
diseases such as diabetes mellitus. Periodontal disease is the $6^{\text {th }}$ complication in people with diabetes mellitus.[4],[5],[6].

Diabetes mellitus (DM) is a disease caused by lack of insulin. The insulin hormone produced by the pancreatic gland is important to maintain the balance of blood sugar levels to remain normal. If there is a work disruption of insulin both quality and quantity, then the balance becomes disturbed and blood sugar will tend to rise. In 2003, around 194 million people suffered from diabetes mellitus throughout the world, reaching $5.1 \%$ of the world population. This number is expected to continue to increase to 333 million people or $6.3 \%$ of the world population in 2025 . Diabetes mellitus is divided into 2 types, type 1 and type 2 . The prevalence of type 2 diabetes mellitus reaches $85 \%$ and sufferers do not experience damage to the pancreas, but it cannot function properly. [5],[6],[7].

Complications of diabetes mellitus that is quite serious in the field of dentistry are oral diabetic, which includes xerostomia, gingivitis, alveolar bone resorption, periodontitis, tooth loss, slow wound healing, oral infections, dental caries, pain in the tongue, dry mouth, burning mouth, dysfunction taste, and saliva, the mouth smells of acetone. Epidemiological studies show that diabetes mellitus increases the risk of alveolar bone loss and attachment loss in periodontal tissues three times greater than non-diabetic mellitus patients. [6],[8].

Blood sugar test can be done at the time of fasting, during and 2 hours after eating. Random blood sugar test is done at any time of the day regardlessof the last meal eaten and the condition of the body of the person. Fasting blood sugar test is a blood sugar check which performed after the patient has fasted for 8-10 hours, while the test of blood sugar levels 2 hours after meals is an examination carried out 2 hours after the patient completes eating. The method used for examining blood sugar consists of a chemical method,enzymatic method, and dry reagent method or strip.[9],[10],[11].

Currently, many devices are marketed for measuring blood sugar levels including glucometer. A glucometer is included in the blood sugar testing tool with the strip method, this tool is quite simple and easy to use. According to Baikler (2002), that the results of examination of blood sugar levels using a glucometer can be trusted. Glucometer (Accu-Chek) can be used to determine blood sugar levels both in patients with diabetes mellitus and non-diabetes mellitus by checking blood sugar through probing when measuring periodontal pockets so that they can be done quickly before periodontal treatment and do not need to do an examination from the fingertips.[12],[13],[14],[15].

Based on this, the authors want to research the examination of blood sugar levels from a periodontal pocket in patients with type 2 diabetes mellitus further.

\section{Methods}

\subsection{Research Tools}

1. Basic instruments

1) Dental mirror

2) Dental explorer

3) Tweezers

4) William's periodontal probe 
5) Cotton rolls

6) Cotton pellets

7) Gargle glass

8) Masks and gloves

9) Stationery

10) Informed consent form

11) Small tray

12) Form results of random blood sugar test

2. Instruments for checking blood sugar

1) 1 set of Accu-chek Performa Nano glucometer

\subsection{Research Materials}

1) Alcohol

2) Blood

3) Handiplast

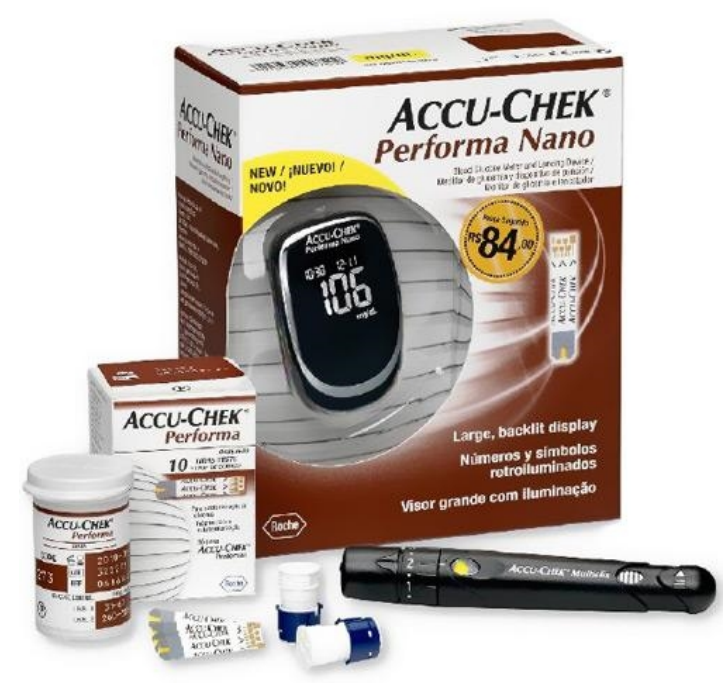

Figure 1. Accu- Chek Glukomater ${ }^{16}$

\subsection{Research Procedures}

1. Patients who come to the clinic of periodontiadepartment who suffer from generalized chronic periodontitis with type 2 diabetes mellitus.

2. The location is isolated with a cotton roll to prevent contamination of saliva.

3. Perform probing using William's Periodontal Probe, the location of which is bleeding the most determined as a source of blood. 
4. After the blood from the periodontal pocket is collected, do the examination by putting the blood to the tip of the test strip on the Accu-Chek Performa Nano glucometer.

5. Record the results of the blood sugar levels printed on the Accu-Chek Performa Nano glucometer's monitor.

6. The location of the fingertipswhich is going to be stabbed is sterilized with gauze containing alcohol.

7. Examination of blood sugar levels from the fingertips with the Accu-Chek Performa Nano glucometer has been attached to the test strip.

8. Record the results of the blood sugar levels printed on the Accu-Chek Performa Nano glucometer's monitor and compare the results.

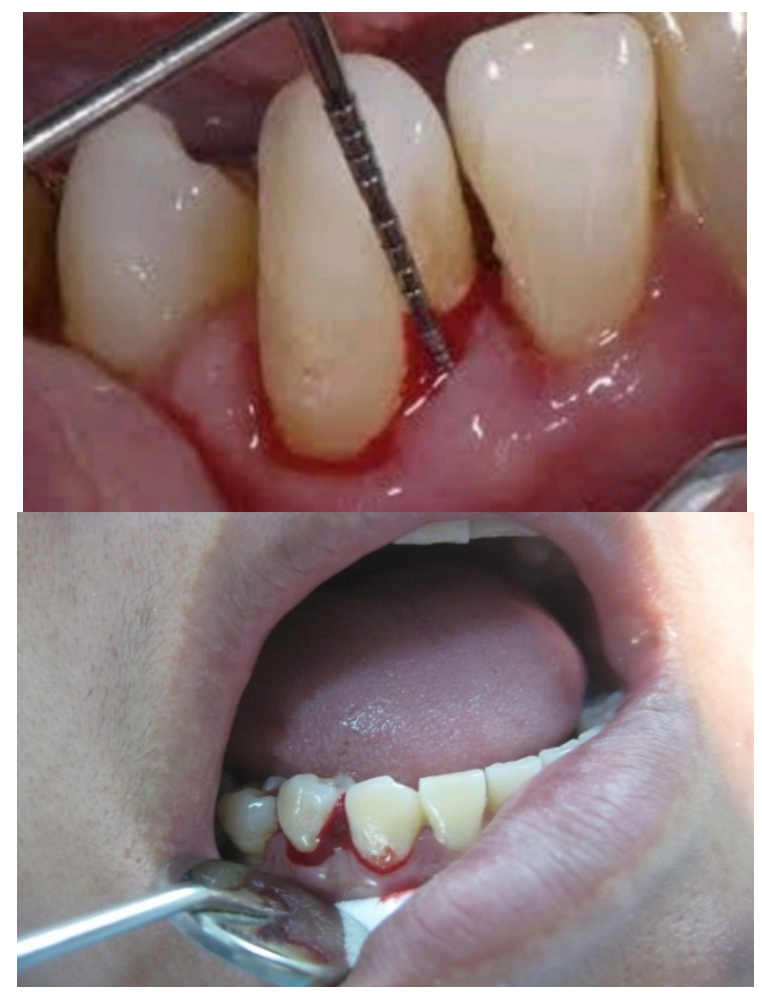

Fig1. Probing to induce gingival bleeding (Bleeding on probing). [16] 


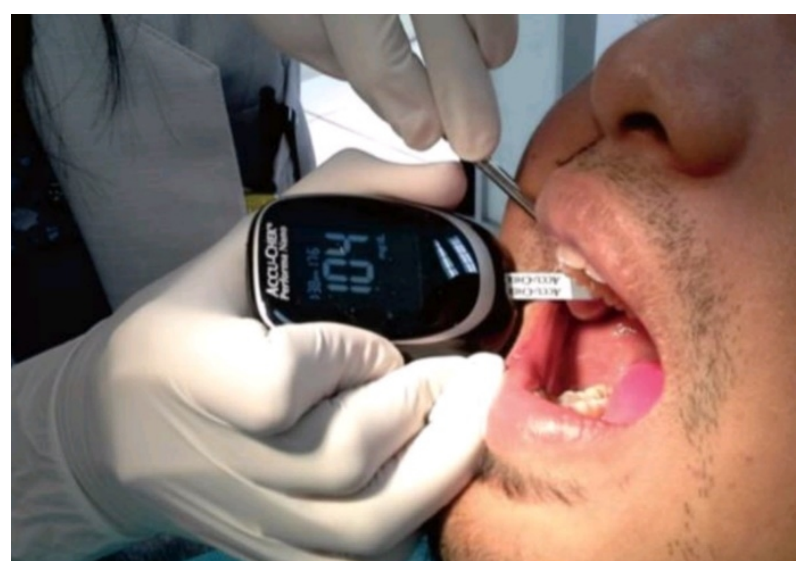

Fig2. Blood collection through the Periodontal Pocket at the time of research

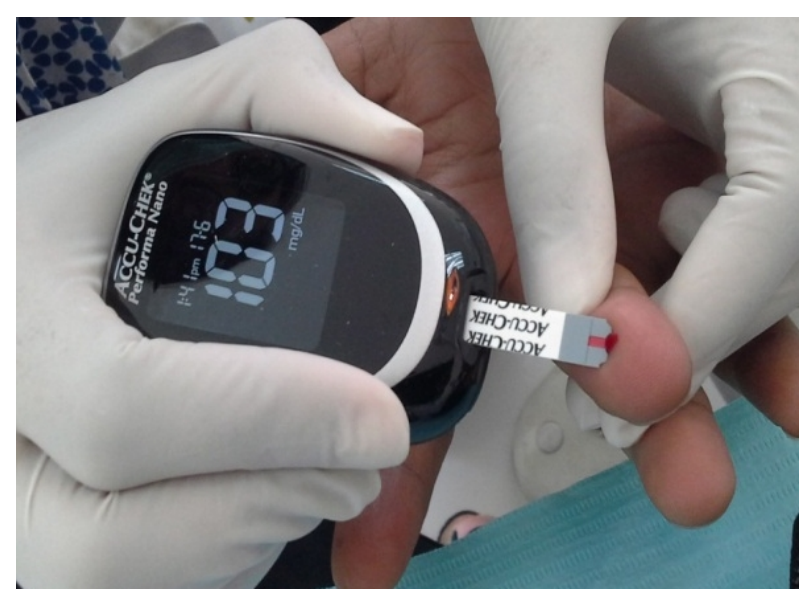

Figure 3. Blood Sugar Levels Test at the Fingertips with a Glucometer at the time of Research

\section{Research Results}

The study was conducted on 10 patients with chronic periodontitis patients with diabetes mellitus and 10 people with chronic periodontitis without diabetes mellitus who came to the clinic RSGM UNPAD of PeriodontiaDepartment who met the inclusion criteria, the inclusion criteria in this study were male and female, existence of periodontal pockets, diabetic patients type 2 with chronic periodontitis. 
Table 1. Examination of Blood Sugar Levels from Periodontal Pocket in Patients with Type 2 Diabetes Mellitus

\begin{tabular}{crrrr}
\hline No & $\begin{array}{c}\text { Blood Sugar level when (mg/d) } \\
\text { Chronic Periodontitis With Diabetes } \\
\text { Mellitus }\end{array}$ & \multicolumn{2}{c}{$\begin{array}{c}\text { Blood Sugar level when (mg/dl) Chronic } \\
\text { Periodontitis Without Diabetes Mellitus }\end{array}$} \\
& Fingertip & Poket Periodontal & Fingertip & Poket Periodontal \\
\hline 1 & 220 & 215 & 85 & 88 \\
2 & 223 & 221 & 90 & 91 \\
3 & 287 & 286 & 95 & 93 \\
4 & 257 & 255 & 89 & 85 \\
5 & 206 & 205 & 91 & 91 \\
6 & 209 & 205 & 103 & 104 \\
7 & 220 & 222 & 134 & 136 \\
8 & 288 & 288 & 142 & 92 \\
9 & 225 & 223 & 93 & 92 \\
10 & 212 & 211 & 90 & \\
\hline
\end{tabular}

Table 2. Differences in Random Blood Sugar Levels (mg/dl) Chronic Periodontitis (CP) with Diabetes Mellitus (DM) and Non-Diabetes Mellitus (Non-DM) Between Fingertips and Periodontal Pocket

\begin{tabular}{|c|c|c|c|c|c|c|}
\hline Condition & Blood collection area & Average & $t$ count & Df & t table & $\begin{array}{l}\text { p-value } \\
\text { (sig) }\end{array}$ \\
\hline \multirow{3}{*}{ DM } & Fingertips & 234.70 & \multirow{3}{*}{0.114} & \multirow{3}{*}{18} & \multirow{3}{*}{2.101} & \multirow{3}{*}{0.911} \\
\hline & & & & & & \\
\hline & Periodontal pocket & 233.10 & & & & \\
\hline \multirow{3}{*}{ Non DM } & Fingertips & 101.20 & \multirow{3}{*}{0.023} & \multirow{3}{*}{18} & \multirow{3}{*}{2.101} & \multirow{3}{*}{0.982} \\
\hline & & & & & & \\
\hline & Periodontal pocket & 101.00 & & & & \\
\hline
\end{tabular}

p-value $\geq 0,05$

The results of this study can be concluded that there is no difference in random blood sugar levels $(\mathrm{mg} / \mathrm{dl})$ in chronic periodontitis either with diabetes mellitus or without diabetes mellitus between fingertips and periodontal pocket with a $p$-value $\geq 0.05$. According to the results of the $t-$ test statistical analysis, the examination of blood sugar levels from the periodontal pocket is the same as the examination of blood sugar levels at the fingertips, so that the examination can be done at the dentist's practice without having to go to the laboratory and check blood sugar during periodontal treatment people with diabetes mellitus as a preliminary phase action (Table.1) 
Table 3. The relation of Blood Sugar Level Between Periodontal Pocket and Fingertips in Chronic Periodontitis (DM) with Diabetes Mellitus (DM) and Non-Diabetes Mellitus (Non-DM).

\begin{tabular}{ccc}
\hline Blood Sugar Value & Correlation (R) & p-value \\
\hline Fingertips and periodontal pocket in type 2 DM & 0.998 & 0.000 \\
\hline Fingertips and periodontal pocket in non-DM & 0.992 & 0.000
\end{tabular}

\section{$\mathrm{p}$-value $\leq 0,05$}

There is a significant relationship to the blood sugar levels test $(\mathrm{mg} / \mathrm{dl})$ in chronic periodontitis both with diabetes mellitus and without diabetes mellitus between fingertips and periodontal pocket with a p-value value 0.05 . According to the results of statistical analysis of Pearson correlation, examination of blood sugar levels from the periodontal pocket is the same as checking blood sugar levels at the fingertips. (Table. 2)

Chart 1. Average Random Blood Sugar Levels (mg/dl) Chronic Periodontitis (CP) with Diabetes Mellitus (DM) and Non-Diabetes Mellitus

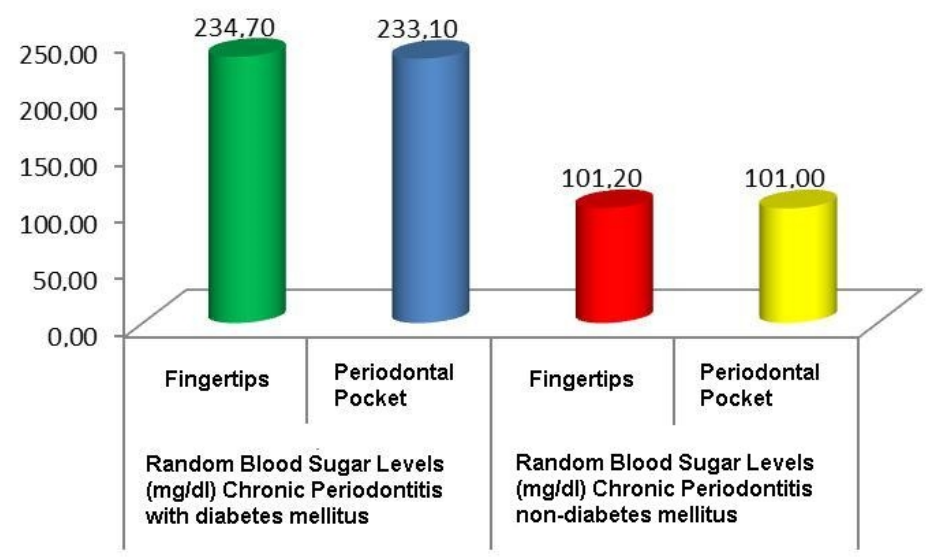

The average value of random blood sugar levels $(\mathrm{mg} / \mathrm{dl})$ chronic periodontitis with diabetes mellitus and non-diabetes mellitus can be seen in Chart 1 . At random blood sugar levels $(\mathrm{mg} / \mathrm{dl})$ chronic periodontitis with diabetes mellitus, the average fingertipswere 234.70 and the periodontal pocket average was 233.10. At random blood sugar levels (mg/dl) chronic periodontitis with nondiabetes mellitus, the average fingertipswere 101.20 and the periodontal pocket average was 101.00 (Chart 1). 


\section{Discussion}

Random blood sugar levels test from the periodontal pocket using Accu-chekperformanano glucometer can be used as an option for examination of blood sugar when dental and oral examinations take place, without having to carry out laboratory tests in advance, according to research from Gupta H. (2012) where blood collection from gingival sulcus is a good source of blood on blood sugar levels using glucometer when treating periodontal tissue and the results of studies on blood sugar levels are generally lower in blood taken from periodontal pocket,it shows thatthere is high contamination of saliva, plaque, and debris. Random blood sugar levels testtaken from the gingival pocket allows contamination of the sulcus fluid and it cannot be avoided. The area to be taken blood is isolated from saliva with a cotton roll and sterile gauze.[16]

This study used ten samples of chronic periodontitis patients with diabetes mellitus and ten samples of chronic periodontitis patients without diabetes mellitus. Each patient was examined for blood sugar levels from the fingertips and periodontal pocket using an Accu-Chek Performa Nano glucometer. Those twenty patients who came to the periodontia department were examined for blood sugar levels taken from the periodontal pocket and fingertips using Accu-chek Performa Nano glucometer. Statistical analysis with Student t-test was used to test for differences in blood sugar levels obtained from the gingival pocket with fingertips and Pearson correlation to assess the relationship of measurement of blood sugar levels obtained from the gingival pocket and the fingertips. The significance of the test results is determined based on $p$ value $\leq 0.05$.

Random blood sugar levels $(\mathrm{mg} / \mathrm{dl})$ in chronic periodontitis with diabetes mellitus $\mathrm{p}$-value $\geq$ 0.05 , then Ho is accepted. Therefore, it can be concluded that there is no difference in blood sugar levels when $(\mathrm{mg} / \mathrm{dl})$ chronic periodontitis with diabetes mellitus between the fingertips and the periodontal pocket. Random blood sugar levels $(\mathrm{mg} / \mathrm{dl})$ in chronic periodontitis with non-diabetes mellitus with p-value value 0.05 , then Ho is accepted. Therefore, it can be concluded that there is no difference in blood sugar levels when $(\mathrm{mg} / \mathrm{dl})$ chronic periodontitis with non-diabetes mellitus between the fingertips and the periodontal pocket. This research was conducted in line with Raghavendra (2010) which stating that capillary blood taken from the periodontal pocket can be a good source for examination of blood sugar.[17],[18].

According to the results of correlation statistical analysis Pearson stated that there is a significant relationship to the examination of blood sugar levels $(\mathrm{mg} / \mathrm{dl})$ in chronic periodontitis both with diabetes mellitus and without diabetes mellitus between fingertips and periodontal pocket with a p-value value 0.05 , where the $p$-value in patients with diabetes mellitus and without diabetes mellitus is 0.000 . This research is in accordance with the results of Beikler et al. (2002) who said that there was a very strong correlation in the examination of blood sugar from the gingival sulcus and from the fingertips in patients with chronic periodontitis accompanied by diabetes mellitus or without accompanied diabetes mellitus.[14].

\section{Conclusion}

Based on the discussion above, the conclusions in this study are that blood sugar levels from the periodontal pocket are the same as blood sugar levels from the fingertips, so that examination of the periodontal pocket can be used as an indicator of blood sugar levels in patients with type 2 diabetes mellitus. 


\section{References}

[1]. Novak JM. Periodontal Disease. In: Newman MG, Takei HH, Klokkevold PR, Carranza FA, editors. Carranza's Clinical Periodontology. 10 ed. Philadelphia: Saunders Elsevier Inc; 2011. p. 434- 9.

[2]. Jones JH, Mason DK. Oral Manifestation of Sistemic Disease. 8 ed. London W.B Saunders Co. Ltd; 1980.

[3]. Tampubolon, Situmorang N. Dampak Karies Gigi dan Penyakit Periodontal Terhadap Kualitas Hidup [updated November 16, 2010].

[4]. International, Diabetes, Federation. Diagnosis and Classification of Diabetes Mellitus 2003 [updated February 25, 2011]. Available from: http://care.diabetesjournals.org/content/27/suppl_1/s5.full.

[5]. Sri H, Mu'afiro A, Suwito J. Analisis faktor yang berhubungan dengan tingkat keparahan periodontitis pada penderita DM tipe 2 di poli diabetes RSU dr. Soetomo Surabaya. Buletin penelitian RSU dr Soetomo. 2008;2(10).

[6]. Daliemunthe SH. Hubungan Timbal Balik Antara Periodontitis dengan Diabates Mellitus. Dentika J Dent. 2003;8(2):120-5.

[7]. Mealey BL, Rethman MP. Periodontal disease and diabetes mellitus. Bidirectional relationship. Dent Today. 2003;22:107-13.

[8]. Darwis Y, dkk. Pedoman Pemeriksaan Laboratorium Untuk Penyakit Diabetes Mellitus. Jakarta: Departemen Kesehatan; 2005.

[9]. Hardjoeno H. Interpretasi Hasiltes Laboratorium Diagnostik. Jakarta: EGC; 2003.

[10]. Novita S. Metode Pemeriksaan Glukosa dalam darah 2013.

[11]. Santora NI. Hematoligi. Jakarta: Pusat Pendidikan Tenaga Kesehatan; 1989.

[12]. Lemon P, Burke K. Medical Surgical Nursing : Critical concepts of disease processes. St Louis: Mosby Year Book. Inc; 2002.

[13]. Perkins. Diabetes and Vigorous Exercise : Applications of Exercise Physiology To Patient Management. Canadian Journal Of Diabetes. 2006;30 (1):63-71.

[14]. Baikler. In- Dental- Office Screen For Diabetes Mellitus Using Gingival Crevicular Blood. J Clinical Periodontology. 2002;29:216-8.

[15]. Prabu S. Realiability of Using Gingival Clevicular Blood in the Diagnosis of Diabetes. JIDS; 2010.

[16]. Jones JH, Mason D. Oral Manifestation of Sistemic Disease. London: W.B. Saunders Co. Ltd; 1980. p. $331-3$.

[17]. Gupta H, Arora R, Kamboj M. The Authenticity of Use of Gingival Elevated Systemic Blood Glucose Level In Undiagnosed Diabetes Meliitus Patients. Indian Journal Of Dental Sciences. 2012;4.

[18]. Raghavendra GNB, Subraya GB. Glucometer as a chairside device to assess bloodglucose in periodontal patients. Journal of the international clinical dental research organization. 2010;2 
